\title{
Do root modules still exist after they die?
}

\author{
Jihong Li ${ }^{\dagger}$, Chengming You ${ }^{\dagger}$, Li Zhang, Han Li, Bo Tan, Yang Liu, Lixia Wang, Sining Liu and Zhenfeng Xu (D)
}

\begin{abstract}
Background: The terminal branch orders of plant root systems are increasingly known as an ephemeral module. This concept is crucial to recognize belowground processes. However, it is unknown if root modules still exist after they die?

Methods: The decomposition patterns of the first five root orders were observed for 3 years using a branch-order classification, a litter-bag method and sequential sampling in a common subalpine tree species (Picea asperata) of southwestern China.

Results: Two root modules were observed during the 3-year incubation. Among the first five branch orders, the first three order roots exhibited temporal patterns of mass loss, nutrients and stoichiometry distinct from their woody mother roots throughout the experimental period. This study, for the first time, reported the decomposition pattern of each individual root order and found a similar decomposition dynamic among ephemeral root branches in a forest tree species.

Conclusions: Results from this study suggest that root modules may also exist after death, while more data are needed for confirmation. The findings may further advance our understanding of architecture-associated functional heterogeneity in the fine-root system and also improve our ability to predict belowground processes.
\end{abstract}

Keywords: Root branch order, Fine roots, Picea asperata, Nitrogen, Phosphorus, Stoichiometry, Root decomposition

\section{Background}

Linking root structures with their functions is very crucial for understanding belowground biogeochemical processes in terrestrial ecosystems (Hishi 2007; McCormack et al. 2015; Lin and Zeng 2017). For several decades, ephemeral roots have generally been treated as a homogeneous mass compartment and defined conveniently as all roots less than a certain diameter (commonly $2 \mathrm{~mm}$ ) (Jackson et al. 1997; Strand et al. 2008). However, even fine roots $(<2 \mathrm{~mm}$ in diameter $)$ can often consist of numerous hierarchies (root orders) (Pregitzer 2002; Guo et al. 2008a). It is increasingly

\footnotetext{
* Correspondence: xuzf@sicau.edu.cn

${ }^{\dagger}$ Jihong Li and Chengming You contributed equally to this work. Forestry Ecological Engineering in the Upper Reaches of the Yangtze River Key Laboratory of Sichuan Province \& National Forestry and Grassland Administration Key Laboratory of Forest Resources Conservation and Ecological Safety on the Upper Reaches of the Yangtze River \& Rainy Area of West China Plantation Ecosystem Permanent Scientific Research Base \& Institute of Ecology and Forestry, Sichuan Agricultural University, Chengdu 611130, China
}

accepted that root traits are functionally linked more to root branching order than to root diameter (Goebel al. 2011; Mucha et al. 2019) 2019a; Wang et al. 2019b; Yan et al. 2019a). Xia et al. had proposed a new approach with root modules termed distal nonwoody lateral branches as ephemeral served similar patterns in a desert ecosystem (Liu et al. 2016). An increasing number of studies have found the modular organization of live root system in diverse woody species (e.g., Guo et al. 2008b; ValenzuelaEstrada et al. 2008; Wang et al. 2011; Guo et al. 2013; 
Sun et al. 2016a; Yan et al. 2019b; Suseela et al. 2020). However, the fate of the different root modules remains unclear after they die.

Despite the importance of root architecture and decomposition, little attention has been paid to root decomposition of different branches because collecting root segments of distal branch orders is commonly very labor-intensive and time-consuming (Kong and $\mathrm{Ma}$ 2014). Global analyses have indicated that fine root decomposition is strongly associated with root tissue chemistry, especially root nitrogen concentration and the ratio of carbon to nitrogen (Silver and Miya 2001; Zhang and Wang 2015). Moreover, several studies have found that mycorrhizal fungi may determine the quality of root litter, and further regulate its decomposition rates in some forest tree species (Langley and Hungate 2003; Goebel et al. 2011). It has been widely proved that lateral branches as a whole exhibited distinct nutritional and mycorrhizal pattern from their higher-order mother roots throughout their life history (e.g. Guo et al. 2008b; Liu et al. 2016). Recent studies have reported the heterogeneity of root decomposition among root order groups in some given tree species (Sun et al. 2013a, 2013b; Sun et al. 2016b; Beidler and Pritchard 2017; Yang et al. 2019). However, in these studies, the first two root orders are often combined into a group (e.g., Fan and Guo 2010; Goebel et al. 2011; Sun et al. 2013a, 2013b; Xiong et al. 2013; Sun et al. 2016b; Yang et al. 2019).

In this study, the specific question addressed is that does root modular organization affect after-life processes? We hypothesized that the ephemeral roots (the first three orders) could have a similar temporal pattern of mass loss, nutrients and stoichiometry distinct from their woody mother roots during the experimental period. In order to test this hypothesis, we explored the decomposition pattern of each individual branch of the first five root orders in a common subalpine forest tree species (Picea asperata) of southwest China.

\section{Methods}

\section{Study site}

This study was conducted at the Long-term Research Station of Forest Ecosystems of the Sichuan Agricultural University, which is located on the eastern Tibetan Plateau, China. The annual mean precipitation and temperature are $850 \mathrm{~mm}$ and $3.0^{\circ} \mathrm{C}$, respectively. In general, seasonal snow cover begins to accumulate in November and melts in March of the following year. $P$. asperata was chosen in this study because it is widely distributed in the area. For this study, a $P$. asperata forest stand was used for a root litter incubation experiment. The basic physicochemical properties of soil $(0-$ $15 \mathrm{~cm}$ ) are as follows: organic carbon $85.7 \mathrm{~g} \cdot \mathrm{kg}^{-1}$, nitrogen $5.7 \mathrm{~g} \cdot \mathrm{kg}^{-1}, \mathrm{pH} 6.2$ and bulk density $1.2 \mathrm{~g} \cdot \mathrm{cm}^{-3}$, respectively.

\section{Root collection and branch order classification}

In June 2013, root segments of $P$. asperata were sampled from a $P$. asperata forest $\left(102.56^{\circ} \mathrm{E}, 31.18^{\circ} \mathrm{N}, 3037 \mathrm{~m}\right.$ a.s.l.) according to the methods of Xiong et al. (2013). Briefly, root branching samples from the upper soil profile $(20 \mathrm{~cm})$ were excavated and then carefully separated lateral root branches from the soil, ensuring the distal root branching orders were still intact. Following the methods of Pregitzer (2002), the distal roots were designated as the first order; the root from which two firstorder roots branched was classified as the second order, and so on. In this study, the first five branching root orders were identified, and the adhering soil particles were gently brushed and removed.

\section{Litterbag incubation, harvest, and analysis}

Air-dried root branches of $1.0000 \pm 0.0010 \mathrm{~g}$ of each order class were placed in litterbags $(5 \mathrm{~cm} \times 5 \mathrm{~cm}$, mesh size $120 \mu \mathrm{m})$. Four plots $(5 \mathrm{~m} \times 5 \mathrm{~m})$ were randomly set up in the original forest. For each root order, duplicate sets of litterbags were placed horizontally at a soil depth of $10 \mathrm{~cm}$ in each plot late in the growing season (midOctober) 2013. One litterbag of each branch order was randomly harvested from each plot on five occasions: early spring 2014 (mid-April), late autumn 2014 (midOctober), early spring 2015, late autumn 2015, and early spring 2016. In the laboratory, soil particles and other extraneous materials were removed. Cleaned roots were oven-dried at $65^{\circ} \mathrm{C}$ to constant mass and weighed.

The root diameter of different branch orders was measured using WinRHIZO image analysis software (Regent Instruments, Quebec, QC, Canada). For each sampling date, specific litters of the same branch order were pooled for chemical analyses after the determination of the dry mass. The concentrations of total carbon (C) in the root samples were determined using the dichromate oxidation-ferrous sulfate titration method and the total nitrogen $(\mathrm{N})$ and phosphorus $(\mathrm{P})$ were measured using the methods of Kjeldahl and phosphomolybdenum yellow spectrophotometry after digestion with hydrogen peroxide and sulfuric acid, respectively.

\section{Data analysis}

Decomposition rates were calculated from dry mass remaining using a single negative exponential decay model: $X_{t} / X_{0}=e^{-k t}$, where $X_{t} / X_{0}$ is the fraction of mass remaining at time $t, t$ the time elapsed in years and $k$ the annual decay constant (Olson 1963). In this study, all variables of two bags within each plot were averaged, and the plot was considered to be the experimental replicate. One-way ANOVA with Fisher's LSD test was used 
to identify significant differences among root orders in initial root traits and constant $k$ value. Repeated measures ANOVA was used to examine the effects of root order, sampling date and their interactions on mass remaining, $\mathrm{N}$ concentration, $\mathrm{P}$ concentration, $\mathrm{C} / \mathrm{N}$ and $\mathrm{C} / \mathrm{P}$. Differences among means were considered significant at the $P<0.05$ level. All statistical tests were performed using the software Statistical Package for the Social Sciences (SPSS) version 16.0.

\section{Results}

\section{Initial root chemistry}

The mean root diameter increased significantly with root branch order, from $0.29 \pm 0.02 \mathrm{~mm}$ in first-order roots to $0.64 \pm 0.07 \mathrm{~mm}$ in fifth-order roots (Table 1). However, both $\mathrm{N}$ and $\mathrm{P}$ concentrations decreased significantly as the root order increased (Table 1). Both $\mathrm{N}$ and $\mathrm{P}$ contents in first-order roots were approximately 2 times higher than those in fifth-order roots. Conversely, the $\mathrm{C} /$ $\mathrm{N}$ and $\mathrm{C} / \mathrm{P}$ ratios increased with increasing root branch order (Table 1).

\section{Mass loss and $k$ value}

The first five order roots of $P$. asperata had a loss of $15 \%-32 \%$ of their initial mass at the end of incubation (Fig. 1a). Statistical analysis showed that both order and season alone had significant effects on root mass remaining over the experimental period (Fig. 1a). In general, root mass remaining tended to decline with root branch order, following a pattern of the fifth-order $<$ the fourth-order $<$ the first three orders (Fig. 1a). However, similar patterns of mass remaining were observed among the first three orders during the experimental period (Fig. 1a). The remaining mass exhibited exponential decreasing trends along with the decomposition time (Fig. $1 \mathrm{~b}, R^{2}$ ranged from 0.88 to 0.93 , all $p<0.001$ ). The values of decay constant (k) did not differ among the first three orders, which, however, were significantly lower than those of the fourth and fifth-order roots (Fig. 1b).

\section{$\mathrm{N}$ and $\mathrm{P}$ concentrations}

Generally, the $\mathrm{N}$ concentrations of the first three order roots increased significantly during the first non- growing season and then began to decrease gradually (Fig. 2a). There were significant differences in initial $\mathrm{N}$ concentration across the first three order roots but the variations among them decreased and even vanished along with the decomposition advancement (Fig. 2a). N concentration was almost identical between fourth and fifth orders over the experimental period. In addition, the seasonal dynamic of $\mathrm{N}$ concentration in fourth and fifth orders was relatively small as compared to the distal branch orders (Fig. 2a). Root order, season and their interaction all showed significant effects on root $\mathrm{N}$ concentration (Fig. 2a).

The $\mathrm{P}$ concentrations of all order roots followed a similar seasonal pattern over the experimental period, with increasing in the non-growing season but decreasing in the growing season (Fig. 2b). The variations in $\mathrm{P}$ concentration among the first three orders were much greater during the first year of incubation as compared to the later stage of decomposition (Fig. 2b). Similar to $\mathrm{N}$ concentration, $\mathrm{P}$ concentrations were similar in both fourth and fifth orders over the experimental period, which were generally lower than those of the first three root orders (Fig. 2b). Statistical analysis indicated that order, season and their interaction all exhibited significant influences on $\mathrm{P}$ concentration (Fig. 2b).

\section{Stoichiometric ratios}

Contrary to $\mathrm{N}$ concentration, the $\mathrm{C} / \mathrm{N}$ ratios significantly decreased over the first year of decomposition then tended to increase gradually (Fig. 3a). The $\mathrm{C} / \mathrm{N}$ ratio increased with increasing root branch orders and this pattern almost existed throughout the whole experiment (Fig. 3a). The $\mathrm{C} / \mathrm{N}$ ratios of the first three order roots were significantly lower than those of the last two orders (Fig. 3a). The seasonality of the $\mathrm{C} / \mathrm{N}$ ratio was similar among the first three orders, which was different from those of higher orders (Fig. 3a). ANOVA analysis showed that the effects of order, season and their interaction were significant on the $\mathrm{C} / \mathrm{N}$ ratio (Fig. 3a).

The C/P ratios of all orders showed a similar seasonal dynamic during the 3-year decomposition, with decreasing in the non-growing season but increasing in the

Table 1 Initial root traits of different branch orders in P. asperata

\begin{tabular}{|c|c|c|c|c|c|}
\hline Root order & Root diameter (mm) & $\mathrm{N}\left(\mathrm{g} \cdot \mathrm{kg}^{-1}\right)$ & $P\left(g \cdot \mathrm{kg}^{-1}\right)$ & $\mathrm{C} / \mathrm{N}$ & $\mathrm{C} / \mathrm{P}$ \\
\hline Order 1 & $0.29 \pm 0.02 c$ & $11.1 \pm 0.4 a$ & $0.81 \pm 0.01 a$ & $30 \pm 2 d$ & $410 \pm 21 d$ \\
\hline Order 2 & $0.33 \pm 0.03 c$ & $9.0 \pm 0.1 b$ & $0.64 \pm 0.01 b$ & $39 \pm 4 c$ & $553 \pm 61 c$ \\
\hline Order 3 & $0.46 \pm 0.04 b$ & $7.7 \pm 0.2 c$ & $0.52 \pm 0.04 c$ & $55 \pm 7 b$ & $815 \pm 92 b$ \\
\hline Order 4 & $0.50 \pm 0.07 b$ & $5.7 \pm 0.1 d$ & $0.49 \pm 0.03 c$ & $81 \pm 5 a$ & $945 \pm 64 b$ \\
\hline Order 5 & $0.64 \pm 0.07 a$ & $5.5 \pm 0.2 d$ & $0.37 \pm 0.03 d$ & $89 \pm 5 a$ & $1322 \pm 94 a$ \\
\hline
\end{tabular}



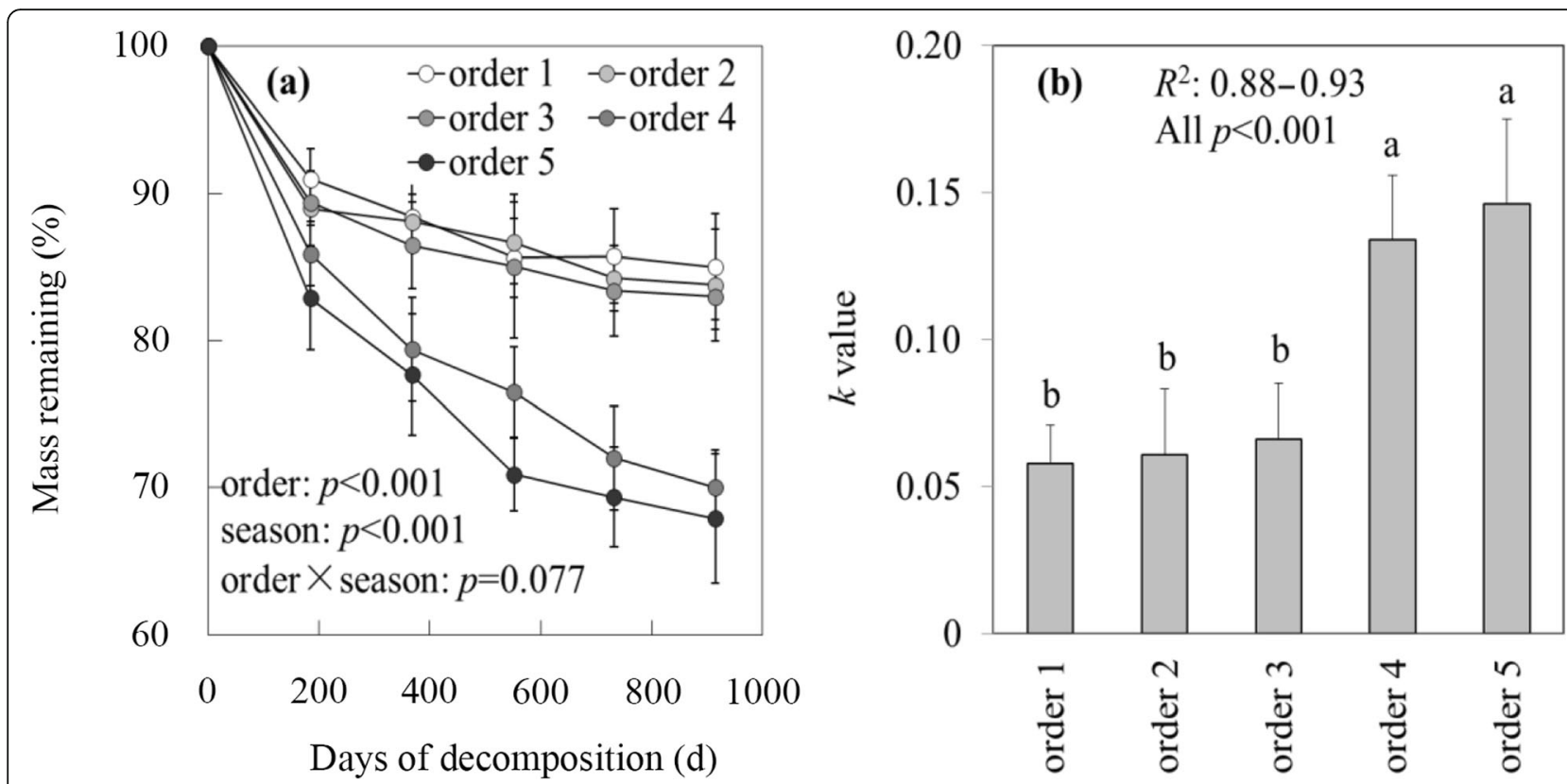

Fig. 1 Mass remaining (\%) and decay constant ( $k$ ) of the first five root branch orders in $P$. asperata during the 3-year decomposition. Values are means \pm S.D.

growing season (Fig. 3b). The variation of the $\mathrm{C} / \mathrm{P}$ ratio in the early stage of decomposition was stronger relative to other stages (Fig. 3b). Except for the initial value, the $\mathrm{C} / \mathrm{P}$ ratio was similar between fourth and fifth orders during the experimental period, which was often greater than those of the first three orders (Fig. 3b). Likewise, the effect of root order on the $\mathrm{C} / \mathrm{P}$ ratio was strongly dependent on seasons (Fig. 3b).

\section{Discussion}

Root decomposition is a critical process in global carbon cycling in terrestrial ecosystems, as it may influence ecosystem productivity via regulating the nutrients cycle (Hobbie 1992). While most of the prior studies on decomposition have mainly focused on aboveground litter, recent evidence suggests that root-derived carbon is retained more efficiently in soils and microorganisms

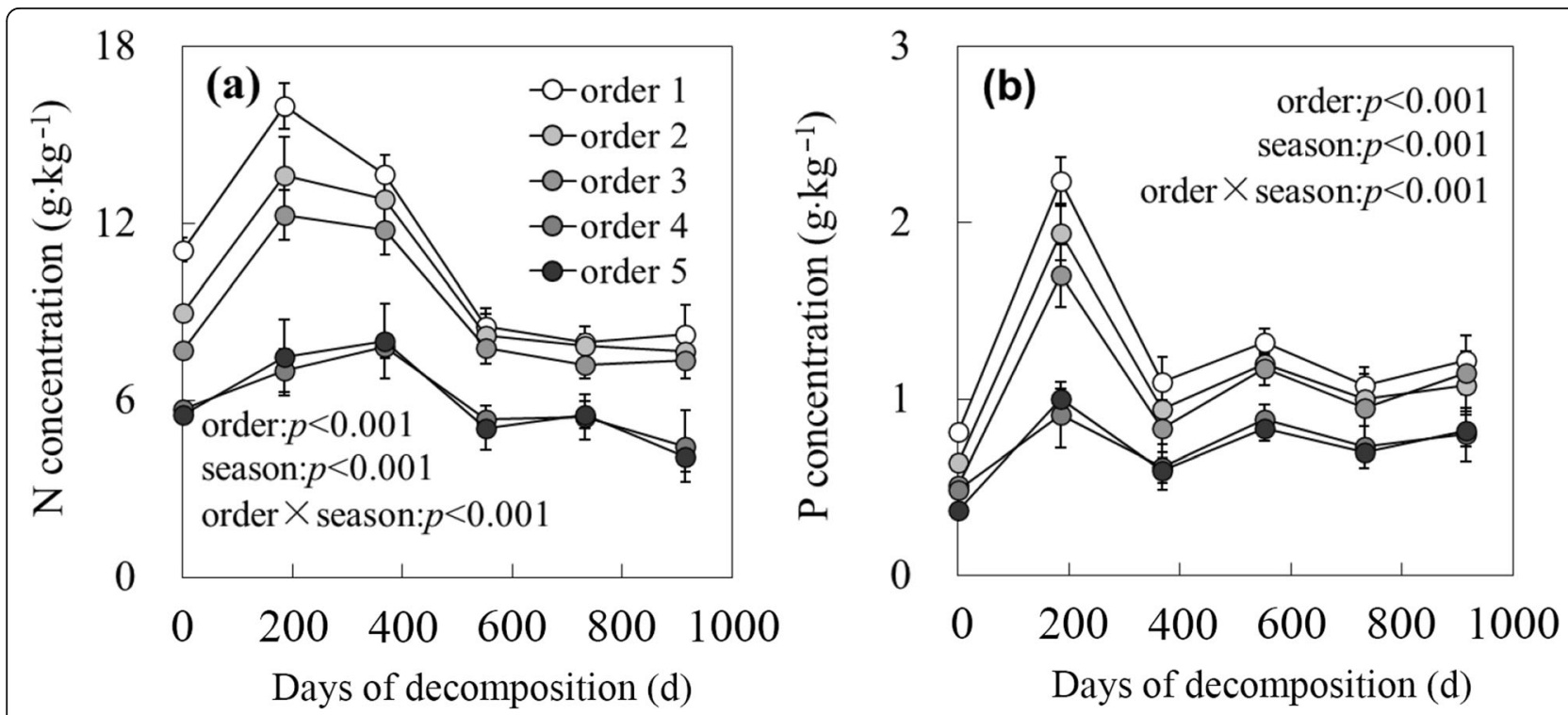

Fig. 2 Seasonal patterns in $\mathrm{N}$ and $\mathrm{P}$ concentrations of the first five root branch orders in $\mathrm{P}$. asperata during the 3-year decomposition period. Values are means \pm S.D. 

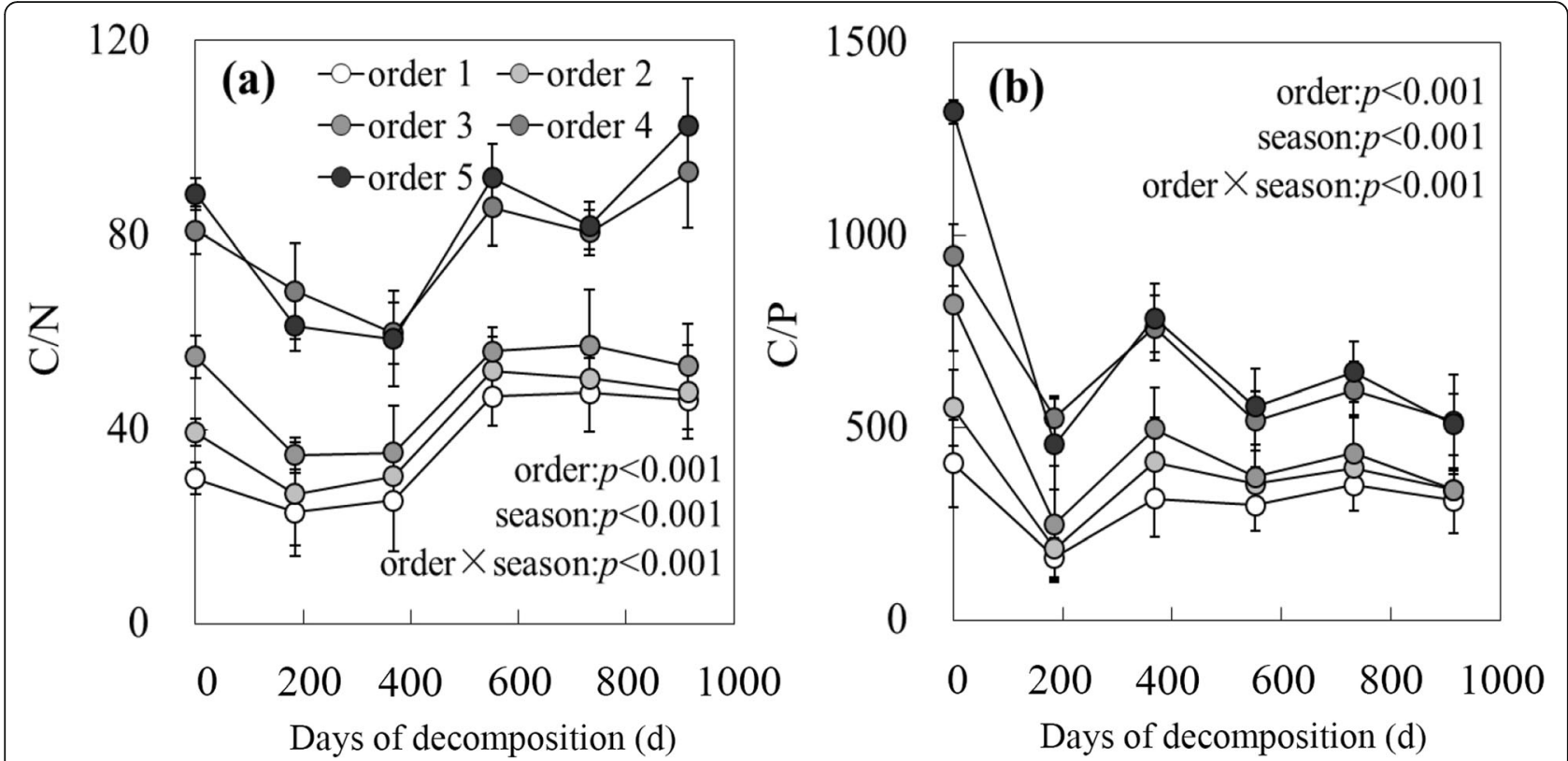

Fig. 3 Seasonal patterns in C/N and C/P ratios of the first five root branch orders in $P$. asperata during the 3-year decomposition period. Values are means \pm S.D.

than that of aboveground plant litter (Kramer et al. 2010; Mendez-Millan et al. 2010). It is increasingly recognized that ephemeral root modules (the most dynamic part) in a root branch is closely associated with some ecological processes as a result of its fast turnover rate, high nutrient content, and strong physiological activity (Xia et al. 2010; Long et al. 2013; Liu et al. 2016). Moreover, given the importance of distal root branch orders in carbon and nutrient cycling during the decomposition process, it gained a great interest in unraveling the decomposition patterns of ephemeral root modules (Xiong et al. 2013; McCormack et al. 2015; Sun et al. 2016b; Yang et al. 2019). However, the pattern of individual order of ephemeral root modules remains unclear after they die.

In this study, the temporal decomposition pattern of each individual order of the first five branches was investigated over the 3-year field incubation using a litter-bag method in a common subalpine tree species ( $P$. asper$a t a)$ of southwestern China. Our data support the hypothesis that root modules did also exist in the decomposition process, at least in $P$. asperata we studied. We could clearly distinguish two types of root modules in mass remaining, nutrient concentration and stoichiometry during the 3-year experiment.

First of all, in $P$. asperata we investigated, lateral branches composed of the first three orders have a significantly slower decomposition rate than their woody mother roots. In addition, this finding was also supported by the decay constant $(k)$ based on an exponential model. The $k$ values were similar among the first three orders, which, however, were lower than those of their woody mother roots (fourth- and fifth-order roots). Thus, the distal root branch orders (the first three orders) and higher-order roots (fourth- and fifth-order roots) may form two contrasting groups within regard to mass loss, suggesting that there is a similar functional trait (i.e., decomposition) within each module group.

Moreover, the distal root branch orders as a whole exhibited a distinct nutritional pattern throughout the 3year decomposition experiment. The first three root orders, which had higher $\mathrm{N}$ and $\mathrm{P}$ concentrations, exhibited marked seasonal patterns in the 3-year decomposition process. On the contrary, the temporal pattern of $\mathrm{N}$ and $\mathrm{P}$ concentrations was relatively slight in the higher-order roots during the experimental period. Therefore, the distal root branch orders and their mother branches consist of two distinct subgroups in $\mathrm{N}$ and $\mathrm{P}$ concentration throughout the 3-year experimental period, implying that a similar function (i.e., nutrient cycling) exists within each module group. Previous studies cannot recognize this phenomenon well, mainly because the root samples used for decomposition experiment are differentiated by diameters (e.g., Sun et al. 2013a, 2013b; Wang et al. 2014; Lin and Zeng 2017) or combined orders (e.g., order $1+$ order 2, Fan and Guo 2010; Goebel et al. 2011; Yang et al. 2019).

Lastly, two root module organizations were also observed in the litter stoichiometry of $\mathrm{C}$ and nutrients along with the decomposition advancement. The distal root branch orders as intact lateral module showed a highly synchronous dynamic in $\mathrm{C} / \mathrm{N}$ and $\mathrm{C} / \mathrm{P}$ in the 
decomposing root litters. A great number of studies have demonstrated that litter quality, particularly the stoichiometry of $\mathrm{C}$ and nutrients as well as the chemistry (i.e. $\mathrm{N}$ and $\mathrm{P}$ concentration), regulate not only rates of litter mass loss, but also the nutrients cycling (i.e., Manzone et al. 2010; Mooshammer et al. 2012; Beidler and Pritchard 2017; Lin and Zeng 2017; Yang et al. 2019). Therefore, the contrasting pattern in nutrients (i.e., $\mathrm{N}$ and $\mathrm{P}$ concentrations) and stoichiometry of $\mathrm{C}$ and nutrients (i.e., $\mathrm{C} / \mathrm{N}$ and $\mathrm{C} / \mathrm{P}$ ) in the decomposing root litters between the distal root branch orders and their mother branches may, to large extent, represent distinct functional traits of mass loss and microbial nutrient release and immobilization.

At the global scale, the roots with higher nutrient concentrations and lower $\mathrm{C}: \mathrm{N}$ ratio may decompose faster (Fernandez and Koide 2014; Zhang and Wang 2015). Our study has found that the $\mathrm{N}$ and $\mathrm{P}$ concentrations decreased but $\mathrm{C} / \mathrm{N}$ and $\mathrm{C} / \mathrm{P}$ ratios increased with increasing root branch order in the initial chemistry of $P$. asperata (Table 1). Therefore, the decomposition rate is expected to decrease with root branch orders in $P$. asperata. On the contrary, over a 3-year observation period, the distal branch order roots (the first three orders) decomposed much slower than their mother branches (the fourth and fifth-order), as reflected by significant order effects (Fig. 1a and b). Several untested underlying mechanisms may be responsible for the observed results. On the one hand, the distal branch order roots are preferentially colonized by fungi and encased by a fungal sheath (Guo et al. 2008b). The fungal sheath is generally fibrous and rich in recalcitrant components (e.g., chitin) (Beidler and Pritchard 2017). Therefore, the physically and chemically resistant boundary of fungal sheaths may need much more time for microbes to break down (Langley et al. 2006). P. asperata noted in our study is a typical tree species with ectomycorrhizal fungi (EM) (Song et al. 2006). Moreover, a considerable number of fungal sheaths had been observed in the lower order roots of $P$. asperata (unpublished data). Our results may also, to some degree, support the mycorrhizal hypothesis, while additional data are needed for confirmation. On the other hand, recent experiments also reported that initial root traits, such as carbon quality and quantity (e.g., total nonstructural carbohydrate and acid-insoluble fraction), nutrient contents (e.g., $\mathrm{N}$ concentration) and recalcitrant components (e.g., tannin), may in part account for the observed slow decomposition of lower-order roots in some given forest tree species (e.g., Fan and Guo 2010; Sun et al. 2013a, 2013b; Fernandez and Koide 2014; Dong et al. 2016; Sun et al. 2016b; Yang et al. 2019), while the underlying mechanisms of specific factors have not been clearly elucidated. Such inconsistent findings imply that diverse mechanisms may regulate the decomposition of the fineroot system. Lastly, some root traits often increase or decrease linearly with increasing branch order (e.g., tissue chemistry) but branch-trait relationships are strongly nonlinear in some cases (e.g., mycorrhizal colonization) (McCormack et al. 2015), which reflect complex controls over the decomposition pattern within a fine-root system.

\section{Implications}

The findings in this study have the following important implications. Firstly, studies have proved that ephemeral live root module generally exists in the distal branches (i.e., the first three-branch orders) through investigating the life-span, respiration, anatomy, and $\mathrm{N}$ concentration of each individual order of fine-root system in some forest tree species (e.g., Guo et al. 2008b; Liu et al. 2016; Wang et al. 2019a; Wang et al. 2019b; Yan et al. 2019a). In recent years, a growing number of studies have examined the heterogeneity in root decomposition among root order groups in some given tree species (e.g., Goebel et al. 2011; Sun et al. 2013a, 2013b; Sun et al. 2016b; Beidler and Pritchard 2017; Yang et al. 2019). In these studies, the first two branch roots were generally combined to a class and the last two (order $3+$ order 4 ) or three (order 3, order 4, order 5) branch roots was combined to another one (e.g., Fan and Guo 2010; Goebel et al. 2011; Sun et al. 2013a, 2013b; Xiong et al. 2013; Sun et al. 2016b; Yang et al. 2019). The segments of distal branch orders (the first two branch roots) seem to have been widely accepted and demonstrated as a functional module organization during the after-life decomposition process. However, no direct available evidence suggests that there are no variations in decomposition rate among the distal branch orders (e.g., the first threebranch roots). Our observations presented in this study indicated that the decomposition dynamic is similar among the first three root branches in $P$. asperata over the 3-year incubation. The results also found that the fine-root system of $P$. asperata can be divided into two modules (the first three orders vs. the last two orders) in the decomposition dynamic. Consistent with this deduction, the distal branch order roots (the first three orders) can be regarded as a relatively independent organization to estimate the belowground root-derived $C$ and nutrients cycling in forest ecosystems dominated by EM tree species, at least in $P$. asperata forest. Additionally, exploring the decomposition patterns of ephemeral root module (the first three orders) could be more accurate and reliable to evaluate the belowground $\mathrm{C}$ and nutrient cycling in some specific forest ecosystems.

Secondly, the two contrasting root modules observed in this study may also imply that collecting root segments of the distal branch orders would not be as labor- 
intensive and time-consuming as before. This is mainly because the first three-branch orders can be considered to be a similar functional organization after death in forest tree species. A recent study has also demonstrated that the hand-kneading approach is a convenient and reliable way to acquire ephemeral root modules (Kong and Ma 2014). It is important to note that the live ephemeral root model occurs in the form of the first two root orders in some shrub species from a desert system (Liu et al. 2016). Therefore, merging the distal three root orders is not necessarily to be the ideal module for all species and sites. Obviously, more plant species associated with EM are badly needed to test the generality of fineroot modules after death.

Finally, a great number of studies have shown that lower-order roots generally had high turnover and mortality rates (e.g., Guo et al. 2008a; Xia et al. 2010; Sun et al. 2016a). However, consistent with the reported results, the mass-loss rates of the distal branch order roots were very slow in the 3-year decomposition as a result of diverse untested mechanisms. Thus, these traits in lower-order roots are likely to be favorable to soil $\mathrm{C}$ and nutrient retention in the forest ecosystems dominated by EM tree species. It should be mentioned that the mesh size of the litterbag used in this study was so fine that efficiently prevents root segment loss from litterbags. However, such a small size could, to some extent, underestimate the decomposition rate due to the absence of soil fauna, especially large-sized and medium-sized soil animals.

\section{Conclusions}

This study explored the temporal patterns of mass loss, nutrients contents and stoichiometry of $\mathrm{C}$ and nutrients of the first five branch order roots in the 3-year decomposition in a common subalpine forest tree species $(P$. asperata) of southwestern China. We provide a piece of evidence that root modules may still exist, at least in the early decomposition of the fine root system of $P$. asperata. Obviously, this study made the further attempt for understanding the structure-function linkage after fineroot death. Certainly, additional detailed work to integrate potential factors and explore their relative importance would help us to better understand and predict root decomposition in forest ecosystems.

\section{Acknowledgements}

We are grateful to the Long-term Research Station of Alpine Forest Ecosystems and the Collaborative Innovation Center of Ecological Security in the Upper Reaches of the Yangtze River, China.

\section{Authors' contributions}

$J H L$ and CMY contributed equally. ZFX conceived the study. ZFX, HL, BT and LXW provided project support. JHL and SNL performed the research and analyzed the data. ZFX, JHL and CMY wrote the manuscript. BT and ZFX contributed to editing. All authors contributed to the work and gave final approval for publication.

\section{Authors' information}

Forestry Ecological Engineering in the Upper Reaches of the Yangtze River Key Laboratory of Sichuan Province \& National Forestry and Grassland Administration Key Laboratory of Forest Resources Conservation and Ecological Safety on the Upper Reaches of the Yangtze River \& Rainy Area of West China Plantation Ecosystem Permanent Scientific Research Base, Institute of Ecology \& Forestry, Sichuan Agricultural University, Chengdu 611130, China.

\section{Funding}

The study was funded by the National Natural Science Foundation of China (Nos. 32071745, 31870602, 31800519 and 31901295), Program of Sichuan Excellent Youth Sci-Tech Foundation (No. 2020JDJQ0052) and the National Key Research and Development Program of China (Nos. 2016YFC0502505 and 2017YF(0505003).

\section{Availability of data and materials}

The datasets used and/or analyzed during the current study are available from the corresponding author on reasonable request.

\section{Declarations}

Ethics approval and consent to participate

Not applicable.

\section{Consent for publication}

Not applicable.

\section{Competing interests}

The authors declare that they have no competing interests.

Received: 23 December 2020 Accepted: 10 March 2021

Published online: 06 April 2021

\section{References}

Beidler KV, Pritchard SG (2017) Maintaining connectivity: understanding the role of root order and mycelial networks in fine root decomposition of woody plants. Plant Soil 420(1-2):19-36. https://doi.org/10.1007/s11104-017-3393-8

Dong L, Mao Z, Sun T (2016) Condensed tannin effects on decomposition of very fine roots among temperate tree species. Soil Biol Biochem 103:489492. https://doi.org/10.1016/j.soilbio.2016.10.003

Fan PP, Guo DL (2010) Slow decomposition of lower order roots: a key mechanism of root carbon and nutrient retention in the soil. Oecologia 163(2):509-515. https://doi.org/10.1007/s00442-009-1541-4

Fernandez CW, Koide RT (2014) Initial melanin and nitrogen concentrations control the decomposition of ectomycorrhizal fungal litter. Soil Biol Biochem 77:150-157. https://doi.org/10.1016/j.soilbio.2014.06.026

Goebel M, Hobbie SE, Bulaj B, Zadworny M, Archibald DD, Oleksyn J, Reich PB, Eissenstat DM (2011) Decomposition of the finest root branching orders: linking belowground dynamics to fine-root function and structure. Ecol Monogr 81(1):89-102. https://doi.org/10.1890/09-2390.1

Guo DL, Li H, Mitchell RJ, Han WX, Hendricks JJ, Fahey TJ, Hendrick RL (2008a) Heterogeneity by root branch order: exploring the discrepancy in root longevity and turnover estimates between minirhizotron and $C$ isotope methods. New Phytol 177(2):443-456. https://doi.org/10.1111/j.1469-8137.2 007.02242.x

Guo DL, Xia MX, Wei X, Chang W, Liu Y, Wang ZQ (2008b) Anatomical traits associated with absorption and mycorrhizal colonization are linked to root branch order in twenty-three Chinese temperate tree species. New Phytol 180(3):673-683. https://doi.org/10.1111/j.1469-8137.2008.02573.x

Guo YY, Wang JJ, Kong DL, Wang W, Guo DL, Wang YB, Xie QL, Liu YS, Zeng H (2013) Fine root branch orders contribute differentially to uptake, allocation, and return of potentially toxic metals. Environ Sci Technol 47(20):1146511472. https://doi.org/10.1021/es4012405

Hishi T (2007) Heterogeneity of individual roots within the fine root architecture: causal links between physiological and ecosystem functions. J Forest Res 12(2):126-133. https://doi.org/10.1007/s10310-006-0260-5

Hobbie SE (1992) Effects of plant species on nutrient cycling. Trends Ecol Evol 7(10):336-339. https://doi.org/10.1016/0169-5347(92)90126-V 
Jackson RB, Mooney HA, Schulze ED (1997) A global budget for fine root biomass, surface area, and nutrient contents. Proc Natl Acad Sci U S A 94(14): 7362-7366. https://doi.org/10.1073/pnas.94.14.7362

Kong DL, Ma CG (2014) Acquisition of ephemeral module in roots: a new view and test. Sci Rep 4(1). https://doi.org/10.1038/srep05078

Kramer C, Trumbore S, Fröberg M, Dozal LMC, Zhang D, Xu X, Santos GM, Hanson PJ (2010) Recent (<4 year old) leaf litter is not a major source of microbial carbon in a temperate forest mineral soil. Soil Biol Biochem 42(7): 1028-1037. https://doi.org/10.1016/j.soilbio.2010.02.021

Langley JA, Chapman SK, Hungate BA (2006) Ectomycorrhizal colonization slows root decomposition: the post-mortem fungal legacy. Ecol Lett 9(8):955-959. https://doi.org/10.1111/j.1461-0248.2006.00948.x

Langley JA, Hungate BA (2003) Mycorrhizal controls on belowground litter quality. Ecology 84(9):2302-2312. https://doi.org/10.1890/02-0282

Lin G, Zeng D (2017) Heterogeneity in decomposition rates and annual litter inputs within fine-root architecture of tree species: implications for forest soil carbon accumulation. Forest Ecol Manag 389:386-394. https://doi.org/10.101 6/j.foreco.2017.01.012

Liu B, He JX, Zeng FJ, Lei JQ, Arndt SK (2016) Life span and structure of ephemeral root modules of different functional groups from a desert system. New Phytol 211(1):103-112. https://doi.org/10.1111/nph.13880

Long YQ, Kong DL, Chen ZX, Zeng H (2013) Variation of the linkage of root function with root branch order. PLoS One 8(2):e57153. https://doi.org/10.13 71/journal.pone.0057153

Manzone S, Trofymow JA, Jackson RB, Porporato A (2010) Stoichiometric controls on carbon, nitrogen, and phosphorus dynamics in decomposing litter. Ecol Monogr 80(1):89-106. https://doi.org/10.1890/09-0179.1

McCormack ML, Dickie IA, Eissensat DM, Fahey TJ, Fernandez CW, Guo D, Helmisaari HS, Hobbie EA, Iversen CM, Jackson RB, Leppälammi-Kujansuu J, Norby RJ, Phillips RP, Pregitzer KS, Pritchard SG, Rewald B, Zadworny M (2015) Redefining fine roots improves understanding of belowground contributions to terrestrial biosphere processes. New Phytol 207(3):505-518. https://doi.org/10.1111/nph.13363

Mendez-Millan M, Dignac MF, Rumpel C, Rasse DP, Derenne S (2010) Molecular dynamics of shoot vs. root biomarkers inan agricultural soil estimated by natural abundance 13C labelling. Soil Biol Biochem 42(2):169-177. https://doi. org/10.1016/j.soilbio.2009.10.010

Mooshammer M, Wanek W, Schnecker J, Wild B, Leitner S, Hofhansl F, Blöchl A Hämmerle I, Frank AH, Fuchslueger L, Keiblinger KM, Zechmeister-Boltenstern S, Richter A (2012) Stoichiometric controls of nitrogen and phosphorus cycling in decomposing beech leaf litter. Ecology 93(4):770-782. https://doi. org/10.1890/11-0721.1

Mucha J, Zadworny M, Helmisaari HS, Nihlgård B, Repo T, Żytkowiak M, Małek S, Reich PB, Oleksyn J (2019) Fine root classification matters: nutrient levels in different functional categories, orders and diameters of roots in boreal Pinus sylvestris across a latitudinal gradient. Plant Soil 447:507-520

Olson JS (1963) Energy storage and the balance of producers and decomposers in ecological systems. Ecology 44(2):322-332. https://doi.org/10.2307/19321 79

Pregitzer KS (2002) Fine roots of trees-a new perspective. New Phytol 154(2):267270. https://doi.org/10.1046/j.1469-8137.2002.00413_1.x

Silver WL, Miya RK (2001) Global patterns in root decomposition: comparisons of climate and litter quality effects. Oecologia 129(3):407-419. https://doi.org/1 $0.1007 /$ s004420100740

Song FQ, Tian XJ, Yang CL, He XB, Chen B, Zhu J, Hao JJ (2006) Ectomycorrhizal infection intensity of subalpine forest ecosystems in western Sichuan, China. Acta Ecol Sin 26:4171-4178

Strand AE, Pritchard SG, McCormack ML, Davis MA, Oren R (2008) Irreconcilable differences: fine-root life spans and soil carbon persistence. Science 319(5862):456-458. https://doi.org/10.1126/science.1151382

Sun K, McCormack ML, Li L, Ma Z, Guo D (2016a) Fast-cycling unit of root turnover in perennial herbaceous plants in a cold temperate ecosystem. Sci Rep 6(1):19698. https://doi.org/10.1038/srep19698

Sun T, Dong L, Zhang L, Wu Z, Wang Q, Li Y, Zhang H, Wang Z (2016b) Early stage fine-root decomposition and its relationship with root order and soil depth in a Larix gmelinii plantation. Forests 7:1-10

Sun T, Mao Z, Dong L, Hou L, Song Y, Wang X (2013a) Further evidence for slow decomposition of very fine roots using two methods: litterbags and intact cores. Plant Soil 366(1-2):633-646. https://doi.org/10.1007/s11104-012-1457-3

Sun T, Mao Z, Han YY (2013b) Slow decomposition of very fine roots and some factors controlling the process: a 4-year experiment in four temperate tree species. Plant Soil 372(1-2):445-458. https://doi.org/10.1007/s11104-013-1 755-4

Suseela V, Tharayil N, Orr G, Hu D (2020) Chemical plasticity in the fine root construct of Quercus spp. varies with root order and drought. New Phytol 228(6):1835-1851. https://doi.org/10.1111/nph.16841

Valenzuela-Estrada LR, Vera-Caraballo V, Ruth LE, Eissenstat DM (2008) Root anatomy, morphology, and longevity among root orders in Vaccinium corymbosum (Ericaceae). Am J Bot 95(12):1506-1514. https://doi.org/10.3 732/ajb.0800092

Wang JJ, Guo YY, Guo DL, Yin SL, Kong DL, Liu YS, Zeng H (2011) Fine root mercury heterogeneity: metabolism of lower-order roots as an effective route for mercury removal. Environ Sci Technol 46:769-777

Wang W, Zhang XY, Tao N, Ao D, Zeng WJ, Qian YQ, Zeng H (2014) Effects of litter types, microsite and root diameters on litter decomposition in Pinus sylvestris plantations of northern China. Plant Soil 374(1-2):677-688. https:// doi.org/10.1007/s11104-013-1902-y

Wang Y, Gao G, Wang N, Wang Z, Gu J (2019a) Effects of morphology and stand structure on root biomass and length differed between absorptive and transport roots in temperate trees. Plant Soil 442(1-2):355-367. https://doi. org/10.1007/s11104-019-04206-7

Wang Y, Li Z, Wang Z, Gu J (2019b) Functional trait plasticity but not coordination differs in absorptive and transport fine roots in response to soil depth. Forests 11(1):42. https://doi.org/10.3390/f11010042

Xia MX, Guo DL, Pregitzer KS (2010) Ephemeral root modules in Fraxinus mandshurica. New Phytol 188(4):1065-1074. https://doi.org/10.1111/j.14698137.2010.03423.x

Xiong YM, Fan PP, Fu SL, Zeng H, Guo DL (2013) Slow decomposition and limited nitrogen release by lower order roots in eight Chinese temperate and subtropical trees. Plant Soil 363(1-2):19-31. https://doi.org/10.1007/s111 04-012-1290-8

Yan G, Zhou M, Wang M, Han S, Liu G, Zhang X, Sun W, Huang B, Wang H, Xing Y, Wang Q (2019a) Nitrogen deposition and decreased precipitation altered nutrient foraging strategies of three temperate trees by affecting root and mycorrhizal traits. Catena 181:104094. https://doi.org/10.1016/j.catena.2019.1 04094

Yan H, Kou L, Wang H, Fu X, Dai X, Li S (2019b) Contrasting root foraging strategies of two subtropical coniferous forests under an increased diversity of understory species. Plant Soil 436(1-2):427-438. https://doi.org/10.1007/ s11104-019-03936-y

Yang S, Cheng R, Xiao W, Shen Y, Wang L, Guo Y, Sun P (2019) Heterogeneity in decomposition rates and nutrient release in fine-root architecture of Pinus massoniana in the three gorges reservoir area. Forests 11(1):14. https://doi. org/10.3390/f11010014

Zhang XY, Wang W (2015) The decomposition of fine and coarse roots: their global patterns and controlling factors. Sci Rep 5(1). https://doi.org/10.1038/ srep09940

\section{Submit your manuscript to a SpringerOpen ${ }^{\circ}$ journal and benefit from:}

- Convenient online submission

- Rigorous peer review

- Open access: articles freely available online

High visibility within the field

Retaining the copyright to your article

Submit your next manuscript at $>$ springeropen.com 